\title{
Photosynthetic and stomatal traits of spike and flag leaf of winter wheat (Triticum aestivum L.) under water deficit
}

\author{
H. DING ${ }^{*}$, D. $\mathrm{LIU}^{* *}$, X. $\mathrm{LIU}^{* * *}$, Y. $\mathrm{LI}^{* *}, \mathrm{~J}_{\mathrm{KANG}}^{* *}, \mathrm{~J} . \mathrm{LV}^{* *,+}$, and G. WANG ${ }^{*,+}$ \\ College of Science, Northwest A\&F University, Yangling, Shaanxi 712100, China* \\ College of Life Sciences, Northwest A\&F University, Yangling, Shaanxi 712100, China** \\ Baoji Institute of Agricultural Sciences, Qishan, Shaanxi 722400, China ${ }^{* * *}$
}

\begin{abstract}
Xerophytic stomatal traits may help plants maintain photosynthetic rates under water deficit; however, such adaptations are not well understood. A pot experiment was conducted with two winter wheat cultivars (Pubing 143, Zhengyin 1) during the grain-filling period. Net photosynthetic rate $\left(P_{\mathrm{N}}\right)$ and chlorophyll $(\mathrm{Chl})$ content were significantly less affected by water deficit in Pubing 143 than that in Zhengyin 1, and the variation in both $P_{\mathrm{N}}$ and Chl content were more stable in spikes compared to flag leaves. At 18 days after anthesis, stomatal conductance of spikes in Pubing 143 were $28 \%$ lower than that of the control, while transpiration rate was 34\% lower in Zhengyin 1 under water deficit. We provided the first evidence of amphistomatous stomata on the lemma of winter wheat spikes through scanning electron microscopic observations. The finding of the amphistomatous stomata is an important contribution to stomatal distribution and may help explain how wheat spikes can maintain high photosynthetic rates even under drought conditions.
\end{abstract}

Additional key words: drought resistance; nonleaf organs; photosynthetic performance; scanning electron microscopy.

\section{Introduction}

Wheat (Triticum aestivum L.) is a globally important cereal crop (Sikder et al. 2015); its production is limited by drought as the most devastating abiotic stress (Royo et al. 1998, Backhaus et al. 2014). In developing countries, the wheat yield is reduced by $50-90 \%$ on at least 600,000 $\mathrm{km}^{2}$ as a result of drought conditions (Skovmand et al. 2001). Poor water availability exists worldwide but is a particular problem in arid and semiarid regions (Wallace 2000, Sikder et al. 2015). Drought stress usually decreases photosynthetic rate (Lawlor 2002) and accelerates leaf senescence (Martinez et al. 2003), resulting in a reduction in the grain yield (Araus et al. 2002), especially if drought occurs at the post-anthesis stage (Wang et al. 2014). Under water stress, the grain-filling process is sustained mainly by photosynthesis in the upper parts of wheat plants, such as the flag leaves and wheat ears (Carr and Wardlaw 1965, Tambussi et al. 2005). Previously, researchers thought photosynthesis of the flag leaves was supplying the majority of assimilates for grain filling (Evans et al. 1975); however, several studies showed that wheat ear (Fig. 1S, supplement available online) is the important source of photosynthetic carbon assimilation during grain filling, especially if plants are under water deficit (Bort et al. 1994, Abbad et al. 2004, Maydup et al. 2012, Jia et al. 2015). Now it is accepted that wheat ear photosynthesis is a major contributor to the final grain yield (Simmons 1987, Araus et al. 1993, Tambussi et al. 2007). Reynolds (2005) proposed that high photosynthesis in wheat spikes was an important trait for drought tolerance in wheat.

Compared to the flag leaves, the photosynthetic rate of wheat ears drops less when wheat is under water deficit conditions (Martinez et al. 2003, Tambussi et al. 2005). There are several traits that likely support the superior photosynthetic performance of wheat ears compared to the flag leaves in wheat under drought conditions. First, the wheat ear is closer to the grain, which is the main photosynthetic sink compared to the flag leaves (O'Brien et al. 1985, Tambussi et al. 2005). Second, the wheat ear could refix the $\mathrm{CO}_{2}$ released by grains during respiration (Kriedeman 1966, Bort et al. 1996, Gebbing and Schnyder

Received 7 August 2016, accepted 13 February 2017, published as online-first 21 March 2017.

${ }^{+}$Corresponding authors; phone:+8613572196187, fax:+8602987092262, e-mail:jinyinlv@nwsuaf.edu.cn; gdwang211@nwsuaf.edu.cn Abbreviations: A - awn; CK - normal water supply conditions; DAA - days after anthesis; DM - dry mass; $E$ - transpiration rate; FB - flag leaf abaxial surface; FM - fresh mass; FV - flag leaf adaxial surface; GF - glume abaxial side; GN - glume adaxial side; $g_{\mathrm{s}}$ - stomatal conductance; LF - lemma abaxial side; LN - lemma adaxial side; MD - moderate water deficit; $P_{\mathrm{N}}$ - net photosynthetic rate; RWC - relative water content; SEM - scanning electron microscopy; TW - turgid mass.

Acknowledgments: This research was financially supported by the National Natural Science Foundation of China (No. 31271624) and Agricultural Science and Technology Innovation and Key Project of Shaanxi Province, China (2016NY-135). 
2001). Third, some degree of $\mathrm{C}_{4}$ or $\mathrm{C}_{3}-\mathrm{C}_{4}$ metabolism exists in the wheat ear (constitutive or drought-induced) (Singal et al. 1986, Ziegler-Jöns 1989a, Imaizumi et al. 1990). Then wheat ear organs even exhibit delayed senescence (Jia et al. 2015). Finally, the wheat ear possesses features of xerophytic adaptation, e.g., xeromorphic anatomy, high water-use efficiency, and osmotic adjustment (Grundbacher 1963, Morgan 1980). Tambussi et al. (2005) demonstrated that the superior performance of wheat ears (compared to flag leaves) may not be explained by $\mathrm{C}_{4}$ or CAM photosynthesis but rather by its higher relative water content (RWC) under water stress. So far, it has not been studied extensively how these xerophytic stomatal adaptations might account for improved photosynthetic performance of wheat ears when plants are under water deficit.

The stomata are microvalves found in aerial plant organs that are responsible for gas exchange, specifically

\section{Materials and methods}

Plant material and water-stress treatment: The present investigation was conducted under controlled environment with two winter wheat (Triticum aestivum L.) genotypes: Pubing 143, a drought-resistant cultivar was identified at the Shaanxi province in September 2004 and is suitable for cropping in arid regions, while Zhengyin 1 was introduced from Italy by Henan Academy of Agricultural Sciences in 1980s (introduction name: st1472/506) and is a droughtsensitive cultivar suitable for nonarid regions.

Pot experiments were carried out in the North Campus of Northwest A\&F University, Yangling $\left(34^{\circ} 17^{\prime} \mathrm{N}\right.$, $108^{\circ} 4^{\prime} \mathrm{E}$ ), Shaanxi Province, China from October 2014 to June 2015. Soil was collected from Shaanxi, a local red loessial soil with a net water content of $29.2 \%$ at the largest field water capacity. Twenty wheat seeds were sowed in each plastic pot ( $24 \mathrm{~cm}$ of upper diameter, $17 \mathrm{~cm}$ of bottom diameter, and $24 \mathrm{~cm}$ in depth), which was filled with $7.5 \mathrm{~kg}$ of soil. Each pot was fertilized with an equivalent of $0.447 \mathrm{~g}$ (urea) $\mathrm{kg}^{-1}$ (soil) and $0.2 \mathrm{~g}\left(\mathrm{KH}_{2} \mathrm{PO}_{4}\right) \mathrm{kg}^{-1}$ (soil). After removing tillers at the jointing stage, the number of the seedlings was reduced to 12 per pot. At the late elongation stage, we initiated the water control by weighing method using irrigation every day. There were two treatments: a control water supply conditions (CK), which maintained pots at a moisture content of $70-75 \%$ of the largest field water capacity, and a moderate water stress treatment (MD), which maintained a moisture content of $45-50 \%$ of the largest field water capacity. There were 16 replicate pots for each treatment. The flag leaves and the wheat ear parts (glumes, lemmas, and awns) were harvested at $0,6,12,18,24$, and $30 \mathrm{~d}$ after anthesis (DAA).

Photosynthetic parameters: Measurements of net photo- acquiring $\mathrm{CO}_{2}$ from the air and transpiring moisture from a plant (Shimada et al. 2011). Araus et al. (1993) detected that glume of the wheat ear had xeromorphic anatomy, which may help wheat accumulate $\mathrm{CO}_{2}$ for photosynthesis. Teare et al. (1972) found stomata on the abaxial side of both lemmas and glumes, but not on the adaxial side. Wheat ears of a spring wheat cultivar also exhibited stomata on the adaxial side of the lemmas and the stomata of glumes were found only on the abaxial surface (ZieglerJöns 1989b). These findings were considered breakthroughs for interpreting the high rates of photosynthesis in spikes, but the debate continued. The aim of this study was to compare the photosynthetic characteristics and stomatal traits of different photosynthetic organs in two wheat cultivars in response to water deficit during the grainfilling stage. We measured the distribution of stomata on the glume, lemma, and awn of the wheat spikes and flag leaves (Figs. 2S-5S, supplement available online).

synthetic rate $\left(P_{\mathrm{N}}\right)$, transpiration rate $(E)$, and stomatal conductance $\left(g_{\mathrm{s}}\right)$ were carried out between 9:00 $\mathrm{h}$ and 11:00 h using a portable photosynthetic system (LI-6400 $X T$, LiCor, USA) with a light intensity of 1,000 $\mu \mathrm{mol}$ (photon) $\mathrm{m}^{-2} \mathrm{~s}^{-1}$ at $0,6,12,18,24$, and 30 DAA with four replicates for each treatment. The chamber was equipped with a red/blue LED light source. When wheat ear photosynthetic parameters were measured, a special cylindrical measuring chamber was connected to the portable photosynthetic system. The surface areas of spikes were calculated according to a previously developed formula of the fringe area (Teare and Peterson 1971): width)

The ear surface area $=3.8 \times[$ (front width + side (ear length)]/2.

Chl content and relative water content: The Chl content was determined according to Arnon (1949) with slight modifications. For each replicate, an approximately $0.1-\mathrm{g}$ sample was harvested, cut into small pieces, placed in a tube, and $10 \mathrm{~mL}$ of $80 \%$ acetone was added. Samples were immediately placed in the dark for $48 \mathrm{~h}$. A 3-mL aliquot of the extract was obtained and absorbance was determined by a UV/VIS spectrophotometer (UV757CRT, Shanghai Precision Scientific Instrument Co., Ltd., China) at $645 \mathrm{~nm}$ and $663 \mathrm{~nm}$.

We measured the relative water content (RWC) in wheat ear parts (glumes, lemmas, and awns) and the blades of the flag leaves. Fresh leaf blade segments or wheat ear parts were weighed for their fresh mass (FM), and weighed again after well-soaking the samples in distilled water at $4^{\circ} \mathrm{C}$ overnight (turgid mass, TM). Samples were then dried for $24 \mathrm{~h}$ at $80^{\circ} \mathrm{C}$ to determine total dry mass (DM). RWC was calculated using the following equation $(\mathrm{Hu}$ et al. 2013): RWC $[\%]=[(\mathrm{FM}-\mathrm{DM}) /(\mathrm{TM}-\mathrm{DM})] \times 100$ 
Scanning electron microscopy (SEM): To prepare samples for SEM, pieces $(5 \times 5 \mathrm{~mm})$ of flag leaves and wheat ear parts were removed with a sharp knife and fixed in cool 4\% glutaraldehyde ( $\mathrm{pH}$ 6.8). The fixed samples were then washed with $0.1 \mathrm{M}$ phosphate buffer to remove glutaraldehyde. Samples were dehydrated by a series of dehydration solutions $(10,30,50,70,80,90$, and $95 \%$ ethanol, each for 10-20 min, and then two rounds of $100 \%$ ethanol, each for 20-30 min). After dehydration, the samples were treated stepwise for $15 \mathrm{~min}$ in mixtures $(75 \%$ ethanol $+25 \%$ isoamyl acetate, $50 \%$ ethanol $+50 \%$ isoamyl acetate, $25 \%$ ethanol $+75 \%$ isoamyl acetate) and finally were soaked in 100\% isoamyl acetate for 30-40 min.

\section{Results}

Net photosynthetic rate and $\mathrm{Chl}$ content: Water deficit had a significant impact on $P_{\mathrm{N}}$ in flag leaves and spikes in both winter wheat genotypes during the grain-filling period (Fig. 1). The $P_{\mathrm{N}}$ of the flag leaves declined during grain-filling in both cultivars, especially in the middle-late grain-filling stage. The decrease in $P_{\mathrm{N}}$ was more significant in Zhengyin 1 compared to Pubing 143. The differences in $P_{\mathrm{N}}$ were $51 \%$ (18 DAA), 67\% (24 DAA), and $75 \%$ (30 DAA) in treated Zhengyin 1 compared with CK. The $P_{\mathrm{N}}$ of spikes was the highest one at 6 DAA and decreased until 30 DAA. Water deficit during postanthesis (18 DAA) induced a greater reduction in spike $P_{\mathrm{N}}$ in Zhengyin 1 (56\%) compared to Pubing 143 (39\%). The impact of water deficit on $P_{\mathrm{N}}$ occurred mainly during postanthesis, and the $P_{\mathrm{N}}$ was more stable in spikes than that in the flag leaves, particularly in Pubing 143 (the droughtresistant cultivar).

In both the control and water-deficit treatments, the $\mathrm{Chl}$ content of the flag leaves and spikes differed depending on the stage of grain filling. Water stress significantly decreased the Chl content of the flag leaves at the late grain-filling stage in both wheat genotypes, but especially in Zhengyin 1. At 24 DAA, the Chl content in the flag leaves declined significantly by $43 \%$ in Pubing 143 and by 97\% in Zhengyin 1. The Chl content of the flag leaves was more sensitive to water deficit in Zhengyin 1 compared to Pubing 143 (Fig. 2A). Because of its location on the upper region of the spikelet, the awn likely received more light and thus contained more $\mathrm{Chl}$ than that in the glume, lemma, or palea. The Chl content of spike parts in both wheat genotypes reached a maximum at 6 DAA and then dropped. Water stress significantly decreased the $\mathrm{Chl}$ content of the glume in both genotypes. In Pubing 143 (the drought-resistant cultivar), the glume $\mathrm{Chl}$ content dropped by $7 \%$ at 24 DAA, whereas in Zhengyin 1 (the droughtsensitive cultivar), it decreased by $24 \%$ (Fig. $2 B$ ). Under
After critical point drying with $\mathrm{CO}_{2}$, samples were pasted on the sample stage, and coated with gold in a sputter coater. Samples were observed and photographed with a $S$-3400N SEM microscope (Hitachi, Japan). According to the actual ratio of obtained images, the size and number of stomata were measured and calculated under a single view $\left(2,230 \mu \mathrm{m}^{2}\right)$.

Statistical analysis: Data were subjected to analysis of variance (ANOVA) separately using Duncan's multiple range test through using $\operatorname{SPSS}(v$. 17.0). Differences at $P<0.05$ were considered statistically significant.

both water regimes, the Chl content was significantly higher in Pubing 143 than that in Zhengyin 1. In addition, under both treatments, awns remained green, especially in the drought-tolerant genotype (Pubing 143).

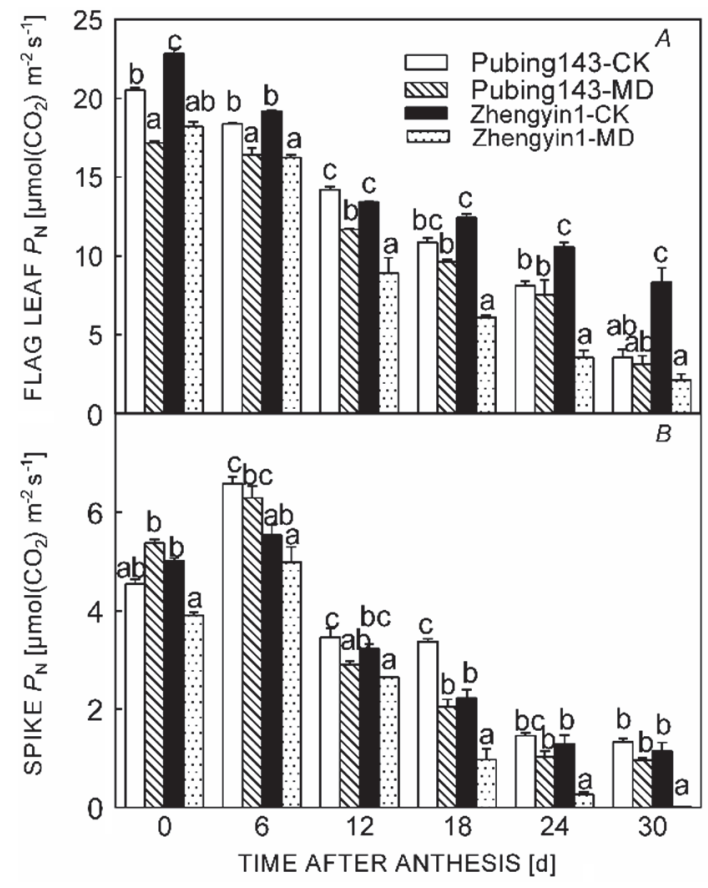

Fig. 1. Net photosynthetic rate $\left(P_{\mathrm{N}}\right)$ of flag leaves $(A)$ and spikes $(B)$ in winter wheat cultivars Pubing 143 and Zhengyin 1 during the grain-filling period. All data represent means \pm standard errors of three replicates. Values with different letters on the same sampling day indicate significant differences at $P<0.05$ level between treatments according to Duncan's multiple range test. CK - normal water supply condition; MD - moderate water deficit. 


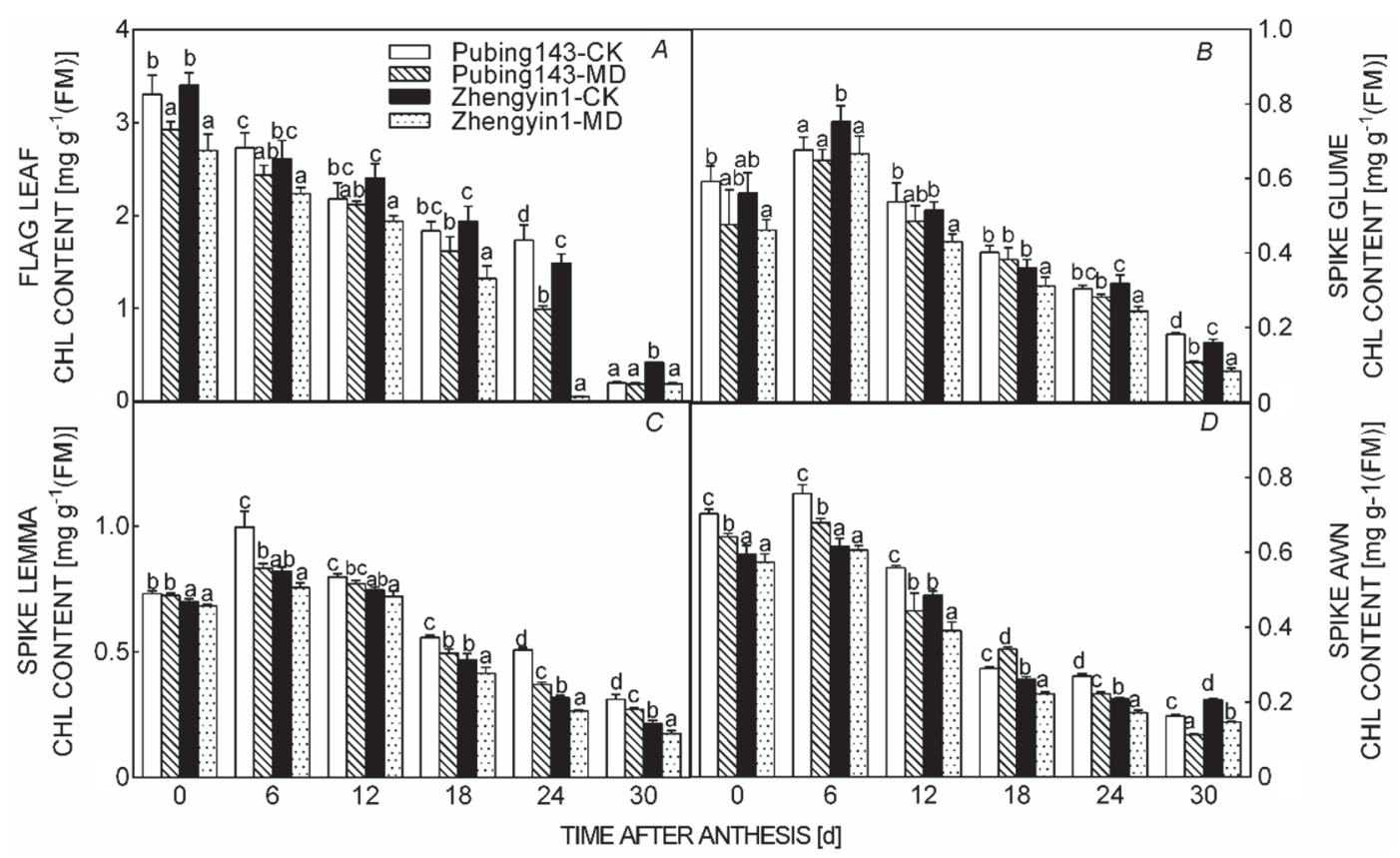

Fig. 2. Chlorophyll content of flag leaves $(A)$ and spikes [glume $(B)$, lemma $(C)$, and awn $(D)$ ] in winter wheat cultivars Pubing 143 and Zhengyin 1 during filling period. All data represent means \pm standard errors of three replicates. Values with different letters on the same sampling day indicate significant differences at $P<0.05$ level between treatments according to Duncan's multiple range test. CK - normal water supply condition; MD - moderate water deficit.

Stomatal conductance: The $g_{\text {s }}$ of the flag leaves in both wheat cultivars declined significantly under MD (Fig. 3). Compared with the CK, $g_{\mathrm{s}}$ of the flag leaves in Zhengyin 1 declined rapidly starting at $12 \mathrm{DAA}$, and was the lowest one at 18 DAA, where it was $76 \%$ lower than that of the CK treatment. Yet, $g_{\text {s }}$ of the flag leaves in Pubing 143 changed only slightly from 12 DAA until 30 DAA. The changes of the trends in $g_{\mathrm{s}}$ for spikes of both wheat genotypes were consistent with the $P_{\mathrm{N}}$ under the MD treatment, which also reached the maximum $g_{\mathrm{s}}$ at 6 DAA. From 12 DAA, the decline of $g_{\mathrm{s}}$ in spikes was significantly higher in Zhengyin 1 than that in Pubing 143. Under MD, the $g_{\mathrm{s}}$ in spikes at 18 DAA was $16 \%$ lower in Pubing 143 and $45 \%$ lower in Zhengyin 1 compared with their respective CK. The $g_{\mathrm{s}}$ in flag leaves and spikes was more sensitive to water deficit in Zhengyin 1 than that in Pubing 143. The gradual trend of $g_{\mathrm{s}}$ maintained a relatively persistent $P_{\mathrm{N}}$ in spikes compared to the flag leaves.

Relative water content: In both winter wheat cultivars, the RWC depletion was significantly different in the flag leaves and spike parts under the MD treatment (Fig. 4). RWC in both cultivars decreased in the flag leaves during the grain-filling period, and this effect was more significant in Zhengyin 1 than that in Pubing 143. Under MD, the flag leaves reduced RWC slightly (by $2 \%$ ) at 24 DAA in Pubing 143, whereas it decreased significantly (by $6 \%$ ) in Zhengyin 1. Generally, under the MD treatment, the RWC of spike parts showed a gradual decrease, whereas the RWC of the flag leaves decreased abruptly. We found little evidence to support that water deficit had a significant effect on the RWC of spike parts in Pubing 143 during the whole grain-filling stages. In Zhengyin 1,

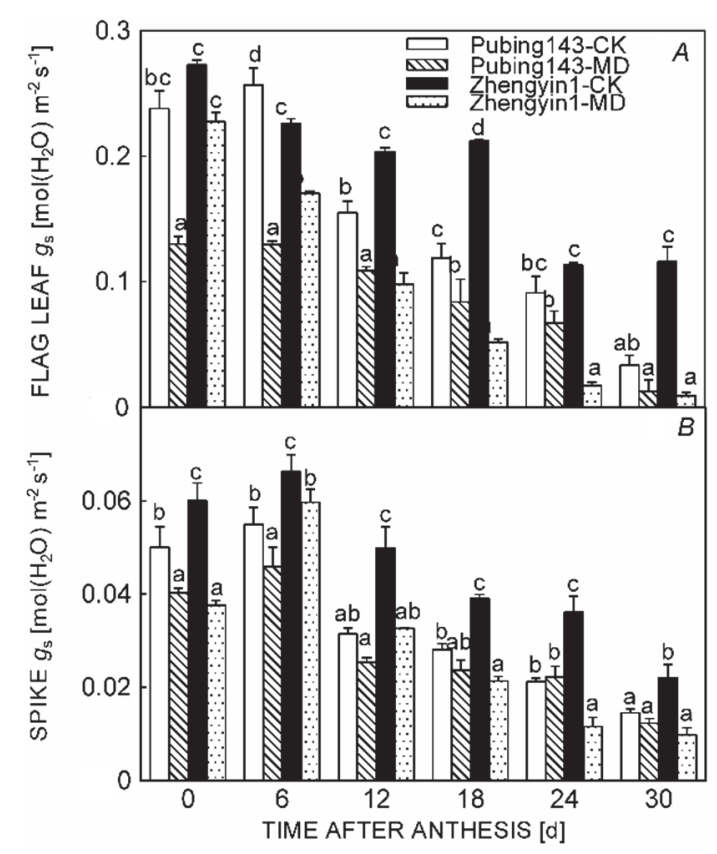

Fig. 3. Stomatal conductance $\left(g_{\mathrm{s}}\right)$ of flag leaves $(A)$ and spikes $(B)$ in winter wheat cultivars Pubing 143 and Zhengyin 1 during filling period. All data represent means \pm standard errors of three replicates. Values with different letters on the same sampling day indicate significant differences at $P<0.05$ level between treatments according to Duncan's multiple range test. CK normal water supply condition; MD - moderate water deficit. 


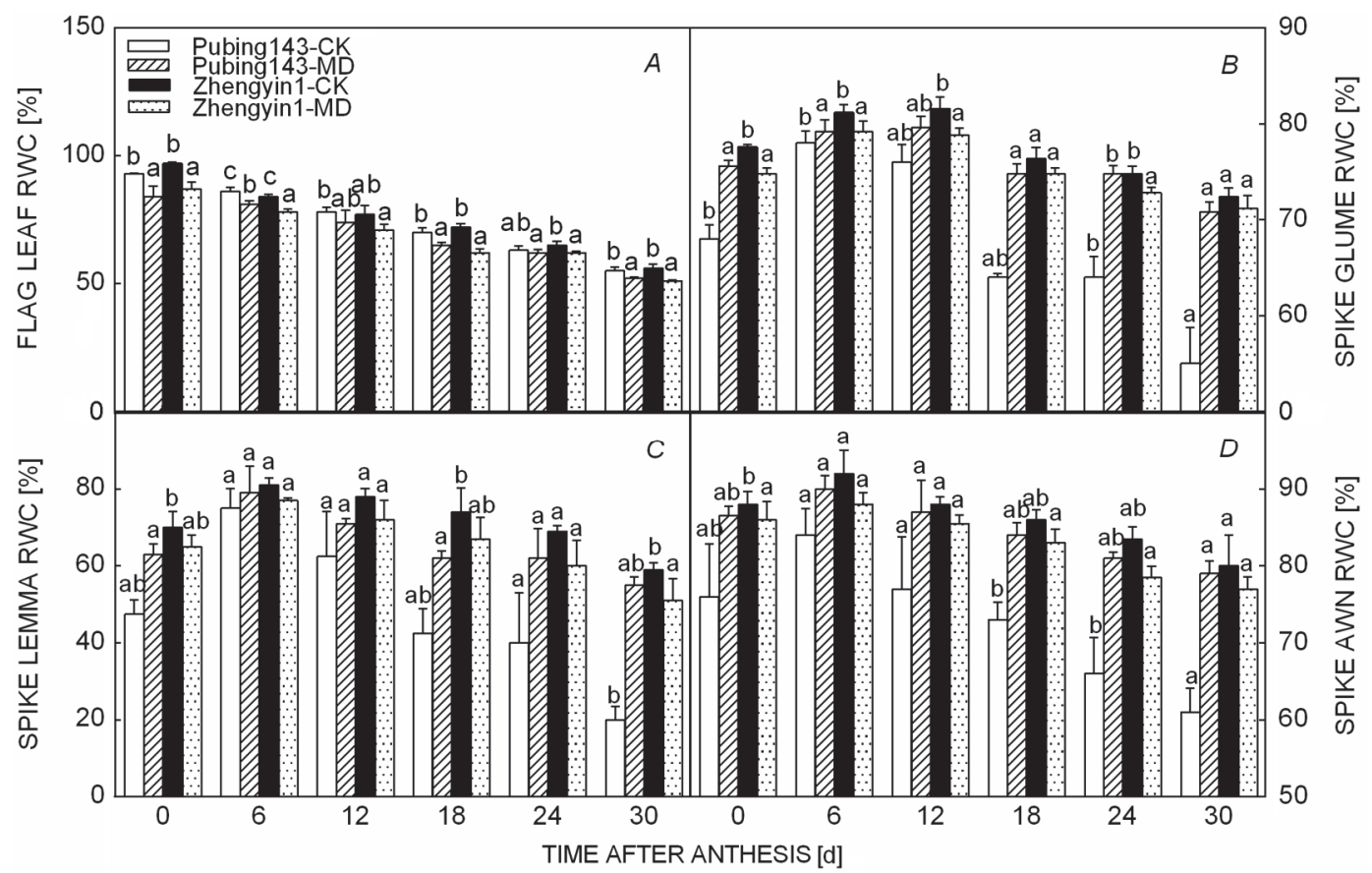

Fig. 4. Effects on relative water content (RWC) of flag leaves $(A)$ and spikes [glume $(B)$, lemma $(C)$, and awn $(D)$ ] in the winter wheat cultivars Pubing 143 and Zhengyin 1 during the grain-filling period. All data represent means \pm standard errors of three replicates. Values with different letters on the same sampling day indicate significant differences at $P<0.05$ level between treatments according to Duncan's multiple range test. CK - normal water supply condition; MD - moderate water deficit.

glume RWC decreased by $8 \%$ at 12 DAA, whereas it only dropped by $2 \%$ in Pubing 143 under MD. Lemma RWC presented no significant difference in both cultivars under drought conditions. Awn RWC declined significantly (by $14 \%$ ) in Zhengyin 1 only at 24 DAA during the grainfilling stage. All these results indicated that spikes had a more stable water retention than that in flag leaves, particularly in drought-tolerant Pubing 143.

Ultrastructure: SEM observations showed that a wax layer covered both the upper and lower surfaces of the flag leaves under all treatment conditions. This wax layer increased on the surface of the flag leaves in both wheat cultivars under MD, most obviously in Pubing 143. Some wax was also present on the spikes and silicified cells on the surface of spike bracts (glumes and lemmas). These observations support the presence of xerophytic traits in winter wheat ears. In both cultivars, stomata were found on the both sides of the flag leaves, arranged in regular rows. We also observed that the glumes and lemmas of wheat ear in both winter wheat varieties were amphistomatous. Stomata on the abaxial side of glumes and lemmas were distributed in orderly rows, whereas stomata on the adaxial side of wheat ear bracts were distributed irregularly, mostly situated over the lower part of the bract surface and distorted by external extrusion mainly from grain development (Figs. 2S-5S, supplements available online).

Stomata number and size: The greatest number of stomata was found on the abaxial side of glumes and lemmas, awns, and flag leaves in both varieties, and only a few stomata were found on the adaxial side of spikes bracts. The stomata number at the lower surface of the flag leaves significantly decreased by $10 \%$ in Pubing 143 and $32 \%$ in Zhengyin 1 at 6 DAA under MD stress. However, there was no obvious influence of water deficit on the stomata number of spike bracts in either cultivar. Stomatal aperture directly impacted the rate of gas exchange, and the length and width reflected the size of the stomatal aperture. Under MD conditions, stomatal aperture of the flag leaves were more responsive in Zhengyin 1 than that in Pubing 143 during the grain-filling period, which corresponded to the $g_{\mathrm{s}}$ in both two genotypes. Water deficit affected less the size of stomatal aperture in wheat ear organs compared to the flag leaves. In Pubing 143, stomatal aperture of wheat ear parts was larger than these in Zhengyin 1 under MD treatment, especially for stomata on the adaxial side of wheat ear bracts (Tables 1-4). This larger aperture of stomata might account for the relatively persistent $P_{\mathrm{N}}$ in spikes of Pubing 143 but not in Zhengyin 1 . 


\section{Discussion}

Several studies have demonstrated that water deficit during grain filling can negatively impact photosynthetic characteristics, reduce the duration of photosynthesis in wheat, and significantly accelerate senescence of flag leaves (Wu et al. 2014, Liu et al. 2016). Increased photosynthesis improves the wheat yield (Parry et al. 2011), whereas water deficit can impair wheat development and yield via insufficient photosynthesis (Guerfel et al. 2009, Jia et al. 2015). In the present study, water-deficit conditions reduced the $P_{\mathrm{N}}$ of the flag leaves and spikes in winter wheat during the grain-filling period, and this effect was significant for the drought-sensitive cultivar. Compared to the continued decrease of $P_{\mathrm{N}}$ in the flag leaves, $P_{\mathrm{N}}$ in spikes changed steadily after anthesis under drought conditions. Martinez et al. (2003) and Tambussi et al. (2005) have shown that $P_{\mathrm{N}}$ of wheat spikes seems to be maintained under water stress compared to the flag leaves, which was consistent with our results. The reduction in the Chl content, which we observed in the flag leaves, indicated earlier senescence during anthesis under water stress treatment, which may result from photoinhibition and photodestruction of pigments and the destabilization of photosynthetic membranes - all of which can be induced by drought conditions (Huseynova 2012). Conversely, the relative stability of the Chl content in spike bracts might help to sustain the duration of spike photosynthesis during the grain-filling period, particularly in drought-resistant cultivars (Martinez et al. 2003).

Stomatal conductance, an important biological process, reflects the carbon accumulation and transpiration in plants with $\mathrm{CO}_{2}$ flowing into sites of photosynthesis via the stomata (Sikder et al. 2015). It is possible that $g_{\mathrm{s}}$ might play an important role in the high $P_{\mathrm{N}}$ under both normal and mild water-stressed conditions (Farquhar and Sharkey

Table 1. Stomatal structure characteristics of the Pubing 143 winter wheat cultivar under normal water supply treatment (CK). All data represent means of six replicates or means $\pm \mathrm{SE}$ of three replicates. The stomata number and stomatal frequency measured through taking nine nonrandom views (each view was 2,230 $\mu \mathrm{m}^{2}$ ) using SEM, could not represent the real stomatal numbers of wheat leaves and spikes. FB - flag leaves abaxial surface, FV - flag leaves adaxial surface, A - awn, GF - glume abaxial side, GN - glume adaxial side, $\mathrm{LF}$ - lemma abaxial side, LN - lemma adaxial side.

\begin{tabular}{|c|c|c|c|c|c|c|c|}
\hline \multirow{2}{*}{$\begin{array}{l}\text { Time after } \\
\text { anthesis [d] }\end{array}$} & \multirow[t]{2}{*}{ Organ } & \multirow{2}{*}{$\begin{array}{l}\text { Stomata number } \\
{\left[\text { No. } 2,230 \mu \mathrm{m}^{-2}\right]}\end{array}$} & \multirow{2}{*}{$\begin{array}{l}\text { Stomatal frequency } \\
{\left[\text { No. } \times 10^{3} \mathrm{~mm}^{-2}\right]}\end{array}$} & \multicolumn{2}{|c|}{ Stomatal aperture $[\mu \mathrm{m}]$} & \multicolumn{2}{|c|}{ Stomatal apparatus size $[\mu \mathrm{m}]$} \\
\hline & & & & Length & Width & Length & Width \\
\hline \multirow{4}{*}{$\begin{array}{l}\text { Pubing } 143 \\
\text { CK }\end{array}$} & FB & 18.00 & 8.07 & $30.22 \pm 2.38$ & $2.14 \pm 0.34$ & $50.54 \pm 1.88$ & $24.75 \pm 1.17$ \\
\hline & FV & 18.67 & 8.37 & $34.58 \pm 3.26$ & $0.34 \pm 0.10$ & $53.31 \pm 1.90$ & $20.81 \pm 3.75$ \\
\hline & A & 15.17 & 6.80 & $26.80 \pm 1.87$ & $2.16 \pm 0.28$ & $43.40 \pm 4.72$ & $20.89 \pm 1.63$ \\
\hline & GF & 23.50 & 10.54 & $18.35 \pm 1.12$ & $1.57 \pm 0.24$ & $36.58 \pm 1.36$ & $21.51 \pm 1.99$ \\
\hline \multirow[t]{7}{*}{0} & GN & 5.50 & 2.47 & $8.51 \pm 0.89$ & $1.73 \pm 0.26$ & $29.83 \pm 3.45$ & $17.72 \pm 3.40$ \\
\hline & $\mathrm{LF}$ & 13.70 & 6.14 & $21.79 \pm 1.46$ & $1.69 \pm 0.15$ & $35.50 \pm 0.63$ & $25.82 \pm 4.99$ \\
\hline & $\mathrm{LN}$ & 6.67 & 2.99 & $12.99 \pm 3.49$ & $2.27 \pm 0.16$ & $27.67 \pm 6.30$ & $21.52 \pm 4.75$ \\
\hline & FB & 13.60 & 6.10 & $29.81 \pm 1.64$ & $2.73 \pm 0.40$ & $52.06 \pm 2.07$ & $24.27 \pm 3.19$ \\
\hline & FV & 20.67 & 9.27 & $33.60 \pm 1.85$ & $0.21 \pm 0.03$ & $52.95 \pm 2.14$ & $21.22 \pm 2.55$ \\
\hline & A & 13.94 & 6.25 & $25.94 \pm 0.57$ & $1.38 \pm 0.12$ & $42.23 \pm 1.39$ & $21.84 \pm 1.93$ \\
\hline & GF & 16.39 & 7.35 & $21.70 \pm 2.47$ & $1.80 \pm 0.12$ & $39.12 \pm 2.21$ & $24.28 \pm 1.72$ \\
\hline \multirow[t]{7}{*}{6} & GN & 4.50 & 2.02 & $8.90 \pm 0.35$ & $1.57 \pm 0.37$ & $28.55 \pm 5.37$ & $15.44 \pm 1.12$ \\
\hline & LF & 8.50 & 3.81 & $22.80 \pm 0.38$ & $1.86 \pm 0.07$ & $39.80 \pm 2.62$ & $24.28 \pm 0.59$ \\
\hline & $\mathrm{LN}$ & 5.90 & 2.65 & $15.94 \pm 1.56$ & $1.73 \pm 0.14$ & $33.32 \pm 0.89$ & $21.07 \pm 1.61$ \\
\hline & FB & 14.25 & 6.39 & $26.68 \pm 1.74$ & $2.26 \pm 0.20$ & $47.11 \pm 1.38$ & $23.99 \pm 1.97$ \\
\hline & $\mathrm{FV}$ & 19.03 & 8.53 & $30.49 \pm 0.73$ & $2.57 \pm 0.28$ & $52.14 \pm 1.13$ & $24.53 \pm 0.33$ \\
\hline & A & 18.28 & 8.20 & $26.88 \pm 1.11$ & $1.16 \pm 0.18$ & $44.84 \pm 2.41$ & $19.44 \pm 0.63$ \\
\hline & GF & 20.50 & 9.19 & $18.43 \pm 0.18$ & $1.64 \pm 0.24$ & $33.54 \pm 0.96$ & $26.55 \pm 0.08$ \\
\hline \multirow[t]{7}{*}{12} & GN & 3.50 & 1.57 & $9.75 \pm 1.00$ & $1.72 \pm 0.15$ & $25.36 \pm 2.17$ & $19.15 \pm 4.68$ \\
\hline & $\mathrm{LF}$ & 14.64 & 6.57 & $19.06 \pm 0.21$ & $1.82 \pm 0.15$ & $36.31 \pm 1.37$ & $22.13 \pm 6.44$ \\
\hline & $\mathrm{LN}$ & 6.22 & 2.79 & $13.69 \pm 0.90$ & $2.26 \pm 0.19$ & $30.14 \pm 2.78$ & $18.75 \pm 1.05$ \\
\hline & FB & 16.50 & 7.40 & $28.36 \pm 1.56$ & $2.63 \pm 0.52$ & $48.97 \pm 1.70$ & $25.31 \pm 0.31$ \\
\hline & $\mathrm{FV}$ & 19.83 & 8.89 & $35.61 \pm 0.43$ & $0.07 \pm 0.01$ & $55.08 \pm 0.83$ & $18.77 \pm 0.48$ \\
\hline & A & 19.67 & 8.82 & $23.04 \pm 2.07$ & $1.33 \pm 0.06$ & $40.75 \pm 3.66$ & $22.86 \pm 1.52$ \\
\hline & GF & 26.85 & 12.04 & $17.62 \pm 0.60$ & $1.97 \pm 0.20$ & $33.22 \pm 1.31$ & $25.34 \pm 2.95$ \\
\hline \multirow[t]{3}{*}{24} & GN & 6.33 & 2.84 & $10.24 \pm 0.83$ & $1.83 \pm 0.30$ & $28.83 \pm 1.13$ & $20.82 \pm 0.50$ \\
\hline & $\mathrm{LF}$ & 15.00 & 6.73 & $14.97 \pm 1.01$ & $1.57 \pm 0.09$ & $33.25 \pm 2.62$ & $20.63 \pm 1.00$ \\
\hline & $\mathrm{LN}$ & 5.83 & 2.62 & $12.65 \pm 0.53$ & $1.73 \pm 0.34$ & $28.44 \pm 0.31$ & $23.11 \pm 3.33$ \\
\hline
\end{tabular}


Table 2. Stomatal structure characteristics of the Pubing 143 winter wheat cultivar under moderate water deficit treatment (MD). All data represent means of six replicates or means \pm SE of three replicates. The stomata number and stomatal frequency measured through taking nine nonrandom views (each view was 2,230 $\mu \mathrm{m}^{2}$ ) using SEM, could not represent the real stomatal numbers of wheat leaves and spikes. FB - flag leaves abaxial surface, FV - flag leaves adaxial surface, A - awn, GF - glume abaxial side, GN - glume adaxial side, LF - lemma abaxial side, LN - lemma adaxial side.

\begin{tabular}{|c|c|c|c|c|c|c|c|}
\hline \multirow{2}{*}{$\begin{array}{l}\text { Time after } \\
\text { anthesis [d] }\end{array}$} & \multirow[t]{2}{*}{ Organ } & \multirow{2}{*}{$\begin{array}{l}\text { Stomata number } \\
{\left[\text { No. } 2,230 \mu \mathrm{m}^{-2}\right]}\end{array}$} & \multirow{2}{*}{$\begin{array}{l}\text { Stomatal frequency } \\
{\left[\text { No. } \times 10^{3} \mathrm{~mm}^{-2}\right]}\end{array}$} & \multicolumn{2}{|c|}{ Stomatal aperture $[\mu \mathrm{m}]$} & \multicolumn{2}{|c|}{ Stomatal apparatus size $[\mu \mathrm{m}]$} \\
\hline & & & & Length & Width & Length & Width \\
\hline \multirow{4}{*}{$\begin{array}{l}\text { Pubing143 } \\
\text { MD }\end{array}$} & FB & 16.33 & 7.32 & $26.33 \pm 1.14$ & $2.83 \pm 0.37$ & $48.93 \pm 2.64$ & $22.87 \pm 0.44$ \\
\hline & $\mathrm{FV}$ & 18.00 & 8.07 & $29.86 \pm 2.50$ & $0.26 \pm 0.11$ & $47.00 \pm 4.43$ & $20.15 \pm 2.27$ \\
\hline & A & 11.06 & 4.96 & $26.96 \pm 0.95$ & $2.10 \pm 0.07$ & $46.04 \pm 2.21$ & $24.44 \pm 3.57$ \\
\hline & GF & 20.33 & 9.12 & $18.41 \pm 0.75$ & $2.34 \pm 0.30$ & $36.09 \pm 1.29$ & $23.47 \pm 1.52$ \\
\hline \multirow[t]{7}{*}{0} & GN & 6.50 & 2.91 & $8.13 \pm 0.75$ & $2.01 \pm 0.19$ & $25.21 \pm 2.39$ & $22.62 \pm 1.44$ \\
\hline & LF & 21.17 & 9.49 & $19.70 \pm 3.96$ & $1.87 \pm 0.08$ & $37.77 \pm 5.53$ & $22.07 \pm 0.93$ \\
\hline & $\mathrm{LN}$ & 4.67 & 2.09 & $12.18 \pm 1.57$ & $2.09 \pm 0.30$ & $26.05 \pm 2.59$ & $18.16 \pm 1.72$ \\
\hline & FB & 15.50 & 6.95 & $27.47 \pm 2.56$ & $2.65 \pm 0.18$ & $50.10 \pm 2.46$ & $27.82 \pm 0.80$ \\
\hline & FV & 18.50 & 8.30 & $25.13 \pm 2.15$ & $0.36 \pm 0.11$ & $44.17 \pm 4.09$ & $21.83 \pm 2.77$ \\
\hline & A & 15.05 & 6.75 & $26.35 \pm 0.96$ & $1.75 \pm 0.30$ & $44.24 \pm 1.20$ & $24.42 \pm 2.97$ \\
\hline & GF & 16.71 & 7.50 & $18.95 \pm 1.75$ & $2.36 \pm 0.28$ & $38.79 \pm 2.75$ & $22.30 \pm 1.97$ \\
\hline \multirow[t]{7}{*}{6} & GN & 4.00 & 1.79 & $5.25 \pm 0.44$ & $1.01 \pm 0.14$ & $22.95 \pm 2.58$ & $14.65 \pm 0.92$ \\
\hline & LF & 20.63 & 9.25 & $20.42 \pm 3.23$ & $2.50 \pm 0.19$ & $39.96 \pm 5.74$ & $21.99 \pm 0.55$ \\
\hline & $\mathrm{LN}$ & 4.40 & 1.97 & $20.10 \pm 0.96$ & $2.31 \pm 0.15$ & $35.30 \pm 0.31$ & $23.91 \pm 1.67$ \\
\hline & FB & 18.50 & 8.30 & $23.42 \pm 0.84$ & $2.11 \pm 0.21$ & $47.45 \pm 0.63$ & $25.19 \pm 2.38$ \\
\hline & FV & 12.00 & 5.38 & $28.47 \pm 2.47$ & $0.15 \pm 0.06$ & $45.76 \pm 1.54$ & $20.68 \pm 1.81$ \\
\hline & $\mathrm{A}$ & 19.50 & 8.74 & $22.08 \pm 1.55$ & $1.30 \pm 0.10$ & $38.11 \pm 0.50$ & $18.52 \pm 0.81$ \\
\hline & GF & 22.83 & 10.24 & $16.09 \pm 0.44$ & $1.74 \pm 0.10$ & $32.64 \pm 0.42$ & $22.91 \pm 1.34$ \\
\hline \multirow[t]{7}{*}{12} & GN & 3.50 & 1.57 & $8.16 \pm 0.51$ & $1.55 \pm 0.12$ & $25.26 \pm 1.01$ & $23.15 \pm 1.77$ \\
\hline & LF & 22.67 & 10.16 & $16.39 \pm 0.69$ & $1.68 \pm 0.19$ & $31.74 \pm 2.84$ & $20.57 \pm 3.76$ \\
\hline & $\mathrm{LN}$ & 5.75 & 2.58 & $13.13 \pm 1.05$ & $2.33 \pm 0.39$ & $32.15 \pm 2.91$ & $20.56 \pm 6.34$ \\
\hline & FB & 17.67 & 7.92 & $32.90 \pm 2.58$ & $2.57 \pm 0.09$ & $50.84 \pm 2.48$ & $24.48 \pm 0.86$ \\
\hline & $\mathrm{FV}$ & 18.13 & 8.13 & $27.34 \pm 8.48$ & $0.51 \pm 0.22$ & $49.19 \pm 6.71$ & $20.67 \pm 2.73$ \\
\hline & A & 11.72 & 5.26 & $27.86 \pm 1.14$ & $2.15 \pm 0.10$ & $46.62 \pm 1.98$ & $24.08 \pm 1.29$ \\
\hline & GF & 25.92 & 11.62 & $16.08 \pm 1.29$ & $1.72 \pm 0.09$ & $33.53 \pm 1.00$ & $21.15 \pm 0.75$ \\
\hline \multirow[t]{3}{*}{24} & GN & 1.00 & 0.45 & $5.64 \pm 0.40$ & $1.81 \pm 0.26$ & $23.46 \pm 4.03$ & $16.37 \pm 2.48$ \\
\hline & LF & 13.70 & 6.14 & $20.08 \pm 1.22$ & $1.67 \pm 0.22$ & $38.23 \pm 1.44$ & $21.89 \pm 2.01$ \\
\hline & $\mathrm{LN}$ & 7.17 & 3.21 & $16.30 \pm 0.20$ & $2.46 \pm 0.27$ & $30.15 \pm 1.23$ & $22.30 \pm 0.90$ \\
\hline
\end{tabular}

1982, Johnson et al. 1987). In the present study, $g_{\text {s }}$ of Pubing 143 showed a lower reduction in both flag leaves and spikes under water deficit compared to Zhengyin 1 during the middle and late grain-filling stages. In contrast, $g_{\mathrm{s}}$ in flag leaves was more sensitive to drought than that of spikes. Saeidi and Abdoli (2015) showed that the decline in $P_{\mathrm{N}}$ may occur due to decreased $g_{\mathrm{s}}$ in wheat, and a similar result was observed in mulberry (Lakshmi et al. 1996) and Plantago lanceolata (Rodgers et al. 2012). However, variations of $g_{\mathrm{s}}$ would produce differences in $E$ for wheat leaves (Morgan and LeCain 1991, Martin et al. 1994). In our study, water deficit reduced $E$ of both flag leaves and spikes in winter wheat. There was the significant decline in Zhengyin 1 in $E$ under drought conditions similarly as in Boogaard et al. (1997). It has been reported that high RWC plays an important role in tolerance to water deficit in wheat (Kraus et al. 1995), and maintaining high RWC capacity seemed to be the main reason of higher drought resistance in the spikes of wheat (Xu and Ishii 1990). Our study showed that the better photosynthetic performance of the spikes was related more to the maintenance of a higher capacity for RWC compared to the flag leaves. Our results also revealed lesser RWC ranges in spikes than those in flag leaves, which may help to maintain high osmotic regulation (Tambussi et al. 2007). Moreover, several studies have concluded that a greater osmotic adjustment capacity and a higher RWC might illustrate the maintenance of persistent photosynthetic activity in spike parts (glumes, lemmas, awns) of drought-resistant cultivars (Wardlaw 2002, Tambussi et al. 2005).

Stomata regulation is closely related to carbon uptake and water loss (Friend and Woodward 1990). Several papers have reported changes in stomatal characteristics and wheat ear photosynthesis under different water regimes (Teare et al. 1972, Shimshi and Ephrat 1975, Flexas and Medrano 2002, Zhang et al. 2006). Zhang et al. (2006) found stomata on the abaxial side of lemmas in two winter wheat cultivars exposed to water deficit conditions, 
Table 3. Stomatal structure characteristics of the Zhengyin 1 winter wheat cultivar under normal water supply treatment (CK). All data represent means of six replicates or means $\pm \mathrm{SE}$ of three replicates. The stomata number and stomatal frequency measured through taking nine nonrandom views (each view was 2,230 $\mu \mathrm{m}^{2}$ ) using SEM, could not represent the real stomatal numbers of wheat leaves and spikes. FB - flag leaves abaxial surface, FV - flag leaves adaxial surface, A - awn, GF - glume abaxial side, GN - glume adaxial side, $\mathrm{LF}$ - lemma abaxial side, LN - lemma adaxial side.

\begin{tabular}{|c|c|c|c|c|c|c|c|}
\hline \multirow{2}{*}{$\begin{array}{l}\text { Time after } \\
\text { anthesis [d] }\end{array}$} & \multirow[t]{2}{*}{ Organ } & \multirow{2}{*}{$\begin{array}{l}\text { Stomata number } \\
{\left[\text { No. } 2,230 \mu \mathrm{m}^{-2}\right]}\end{array}$} & \multirow{2}{*}{$\begin{array}{l}\text { Stomatal frequency } \\
{\left[\text { No. } \times 10^{3} \mathrm{~mm}^{-2}\right]}\end{array}$} & \multicolumn{2}{|c|}{ Stomatal aperture $[\mu \mathrm{m}]$} & \multicolumn{2}{|c|}{ Stomatal apparatus size $[\mu \mathrm{m}]$} \\
\hline & & & & Length & Width & Length & Width \\
\hline \multirow{4}{*}{$\begin{array}{l}\text { Zhengyin } 1 \\
\text { CK }\end{array}$} & FB & 13.83 & 6.20 & $26.95 \pm 1.68$ & $2.15 \pm 0.16$ & $44.53 \pm 1.62$ & $27.78 \pm 0.90$ \\
\hline & FV & 19.17 & 8.59 & $28.45 \pm 3.00$ & $0.54 \pm 0.13$ & $46.96 \pm 1.85$ & $26.90 \pm 2.29$ \\
\hline & A & 10.67 & 4.78 & $23.31 \pm 3.50$ & $2.49 \pm 1.05$ & $41.80 \pm 1.25$ & $25.36 \pm 1.12$ \\
\hline & GF & 23.10 & 10.36 & $21.60 \pm 0.91$ & $1.46 \pm 0.36$ & $39.24 \pm 0.90$ & $25.48 \pm 1.76$ \\
\hline \multirow[t]{7}{*}{0} & GN & 4.00 & 1.79 & $11.71 \pm 1.38$ & $1.24 \pm 0.40$ & $26.12 \pm 1.46$ & $27.08 \pm 1.76$ \\
\hline & LF & 10.67 & 4.78 & $22.45 \pm 1.36$ & $1.78 \pm 0.44$ & $39.07 \pm 1.05$ & $22.47 \pm 1.56$ \\
\hline & $\mathrm{LN}$ & 4.00 & 1.79 & $15.52 \pm 2.15$ & $1.27 \pm 0.29$ & $31.63 \pm 2.25$ & $22.21 \pm 4.47$ \\
\hline & FB & 17.17 & 7.70 & $23.35 \pm 0.70$ & $1.98 \pm 0.02$ & $43.47 \pm 1.51$ & $27.98 \pm 0.29$ \\
\hline & FV & 24.83 & 11.14 & $27.76 \pm 0.94$ & $0.49 \pm 0.10$ & $47.92 \pm 1.81$ & $25.69 \pm 1.56$ \\
\hline & A & 19.50 & 8.74 & $25.39 \pm 2.52$ & $1.86 \pm 0.19$ & $44.09 \pm 1.04$ & $21.66 \pm 2.86$ \\
\hline & GF & 15.19 & 6.81 & $20.58 \pm 1.19$ & $1.78 \pm 0.10$ & $37.26 \pm 3.85$ & $28.73 \pm 1.76$ \\
\hline \multirow[t]{7}{*}{6} & GN & 4.00 & 1.79 & $12.52 \pm 1.76$ & $1.24 \pm 0.26$ & $25.40 \pm 3.98$ & $26.00 \pm 3.86$ \\
\hline & $\mathrm{LF}$ & 18.67 & 8.37 & $19.37 \pm 1.86$ & $1.96 \pm 0.18$ & $35.98 \pm 1.71$ & $26.01 \pm 3.22$ \\
\hline & $\mathrm{LN}$ & 3.00 & 1.35 & $15.30 \pm 3.10$ & $1.27 \pm 0.19$ & $29.16 \pm 6.54$ & $27.64 \pm 4.69$ \\
\hline & FB & 20.00 & 8.97 & $28.70 \pm 0.90$ & $2.32 \pm 0.17$ & $49.10 \pm 1.32$ & $28.42 \pm 1.24$ \\
\hline & $\mathrm{FV}$ & 23.00 & 10.31 & $36.23 \pm 1.39$ & $0.86 \pm 0.16$ & $53.34 \pm 0.67$ & $25.33 \pm 0.73$ \\
\hline & A & 16.33 & 7.32 & $24.03 \pm 0.61$ & $1.63 \pm 0.13$ & $40.46 \pm 0.30$ & $21.37 \pm 0.40$ \\
\hline & GF & 19.63 & 8.80 & $23.50 \pm 0.82$ & $1.90 \pm 0.13$ & $40.61 \pm 0.27$ & $30.35 \pm 4.58$ \\
\hline \multirow[t]{7}{*}{12} & GN & 4.00 & 1.79 & $11.45 \pm 0.13$ & $0.68 \pm 0.04$ & $22.21 \pm 0.51$ & $30.52 \pm 2.08$ \\
\hline & $\mathrm{LF}$ & 11.40 & 5.11 & $22.04 \pm 1.53$ & $1.40 \pm 0.12$ & $38.81 \pm 1.88$ & $25.47 \pm 3.55$ \\
\hline & $\mathrm{LN}$ & 4.67 & 2.09 & $13.67 \pm 1.26$ & $1.15 \pm 0.03$ & $26.57 \pm 1.33$ & $20.93 \pm 2.86$ \\
\hline & FB & 18.83 & 8.45 & $32.46 \pm 0.84$ & $2.76 \pm 0.13$ & $50.55 \pm 0.56$ & $30.35 \pm 0.25$ \\
\hline & FV & 20.25 & 9.08 & $31.39 \pm 0.43$ & $0.95 \pm 0.07$ & $50.91 \pm 0.46$ & $21.70 \pm 0.05$ \\
\hline & A & 14.17 & 6.35 & $23.46 \pm 1.73$ & $1.67 \pm 0.03$ & $40.83 \pm 1.11$ & $25.24 \pm 1.49$ \\
\hline & GF & 16.80 & 7.53 & $21.59 \pm 1.51$ & $1.53 \pm 0.17$ & $37.28 \pm 1.25$ & $28.10 \pm 1.31$ \\
\hline \multirow[t]{3}{*}{24} & GN & 5.00 & 2.24 & $9.99 \pm 0.40$ & $1.10 \pm 0.05$ & $25.99 \pm 0.78$ & $25.72 \pm 1.15$ \\
\hline & $\mathrm{LF}$ & 12.70 & 5.70 & $25.19 \pm 1.70$ & $1.79 \pm 0.07$ & $41.19 \pm 0.51$ & $24.42 \pm 1.74$ \\
\hline & $\mathrm{LN}$ & 5.50 & 2.47 & $14.83 \pm 1.72$ & $1.50 \pm 0.24$ & $30.54 \pm 2.18$ & $25.62 \pm 3.83$ \\
\hline
\end{tabular}

whereas more stomata were observed on the adaxial side of lemmas of wheat plants under well-watered conditions. Ziegler-Jöns (1989b) found discordant results when examining the stomatal distribution of wheat ear bracts in spring wheat. It is worth noting that we observed that stomata occurred on both abaxial side and adaxial side of wheat ear bracts in winter wheat under moderate water deficit, where they were distributed over the lower part of the adaxial surface. The trait of stomata on the adaxial surface might help to assimilate $\mathrm{CO}_{2}$ released from grain respiration, and the recycling of respired $\mathrm{CO}_{2}$ had been considered a key process for total assimilation in the wheat ear (Kriedeman 1966, Bort et al. 1996, Gebbing and Schnyder 2001). Thus, under water deficit during grainfilling, the relatively high capacity of photosynthesis and water retention in Pubing 143 may be explained by lesser difference in stomatal aperture, the distinct space position of stomata, and the relative 'stay-green' trait of wheat ears.

Conclusion: For two winter wheat cultivars, photosynthetic parameters, chlorophyll content, and RWC of the flag leaves and spikes were found to be affected by moderate water deficit during the grain-filling period. This is the first observation of amphistomatous stomatal traits in the lemma of wheat spikes and it may enhance our understanding of stomatal distribution and high rates of photosynthesis in the upper region of grain spikes, particularly in drought-resistant cultivars. The relationship between the superior photosynthetic performance of wheat ears and potential xerophytic adaptations requires further research. 
Table 4. Stomatal structure characteristics of the Zhengyin 1 winter wheat cultivar under moderate water deficit (MD). All data represent the means of six replicates or means $\pm \mathrm{SE}$ of three replicates. The stomata number and stomatal frequency measured through taking nine nonrandom views (each view was $2,230 \mu \mathrm{m}^{2}$ ) using SEM, could not represent the real stomatal numbers of wheat leaves and spikes. FB - flag leaves abaxial surface, FV - flag leaves adaxial surface, A - awn, GF - glume abaxial side, GN - glume adaxial side, LF lemma abaxial side, $\mathrm{LN}$ - lemma adaxial side.

\begin{tabular}{|c|c|c|c|c|c|c|c|}
\hline \multirow{2}{*}{$\begin{array}{l}\text { Time after } \\
\text { anthesis [d] }\end{array}$} & \multirow[t]{2}{*}{ Organ } & \multirow{2}{*}{$\begin{array}{l}\text { Stomata number } \\
{\left[\text { No. } 2,230 \mu^{-2}\right]}\end{array}$} & \multirow{2}{*}{$\begin{array}{l}\text { Stomatal frequency } \\
{\left[\text { No. } \times 10^{3} \mathrm{~mm}^{-2}\right]}\end{array}$} & \multicolumn{2}{|c|}{ Stomatal aperture $[\mu \mathrm{m}]$} & \multicolumn{2}{|c|}{ Stomatal apparatus size $[\mu \mathrm{m}]$} \\
\hline & & & & Length & Width & Length & Width \\
\hline \multirow{4}{*}{$\begin{array}{l}\text { Zhengyin 1 } \\
\text { MD }\end{array}$} & FB & 17.33 & 7.77 & $35.63 \pm 1.67$ & $3.70 \pm 0.16$ & $53.26 \pm 0.87$ & $27.41 \pm 0.93$ \\
\hline & $\mathrm{FV}$ & 16.13 & 7.23 & $33.52 \pm 1.71$ & $0.66 \pm 0.03$ & $49.82 \pm 2.52$ & $20.64 \pm 1.15$ \\
\hline & A & 14.50 & 6.50 & $27.53 \pm 1.38$ & $2.13 \pm 0.11$ & $46.62 \pm 1.18$ & $16.67 \pm 2.21$ \\
\hline & GF & 10.90 & 4.89 & $20.07 \pm 1.78$ & $1.55 \pm 0.03$ & $36.19 \pm 1.31$ & $24.44 \pm 2.81$ \\
\hline \multirow[t]{7}{*}{0} & GN & 3.00 & 1.35 & $13.44 \pm 0.71$ & $1.68 \pm 0.09$ & $29.25 \pm 0.83$ & $25.72 \pm 3.91$ \\
\hline & LF & 10.20 & 4.57 & $23.75 \pm 1.53$ & $1.61 \pm 0.11$ & $39.11 \pm 1.06$ & $24.53 \pm 3.14$ \\
\hline & $\mathrm{LN}$ & 6.13 & 2.75 & $14.90 \pm 0.89$ & $1.12 \pm 0.05$ & $29.36 \pm 2.18$ & $21.39 \pm 2.05$ \\
\hline & FB & 17.00 & 7.62 & $32.88 \pm 0.60$ & $3.13 \pm 0.35$ & $51.70 \pm 0.94$ & $29.32 \pm 1.80$ \\
\hline & $\mathrm{FV}$ & 17.00 & 7.62 & $30.51 \pm 5.13$ & $0.27 \pm 0.05$ & $48.19 \pm 4.28$ & $21.40 \pm 0.34$ \\
\hline & A & 20.33 & 9.12 & $25.93 \pm 1.32$ & $1.66 \pm 0.13$ & $42.88 \pm 1.55$ & $18.67 \pm 1.52$ \\
\hline & GF & 18.83 & 8.45 & $20.87 \pm 1.00$ & $1.85 \pm 0.36$ & $37.72 \pm 0.98$ & $25.31 \pm 1.80$ \\
\hline \multirow{7}{*}{6} & GN & 6.83 & 3.06 & $14.69 \pm 1.48$ & $1.82 \pm 0.13$ & $31.48 \pm 1.54$ & $24.12 \pm 2.61$ \\
\hline & $\mathrm{LF}$ & 14.50 & 6.50 & $25.52 \pm 1.20$ & $0.93 \pm 0.11$ & $41.41 \pm 0.39$ & $25.46 \pm 0.96$ \\
\hline & $\mathrm{LN}$ & 4.75 & 2.13 & $15.54 \pm 0.45$ & $1.09 \pm 0.10$ & $28.73 \pm 1.21$ & $24.75 \pm 3.11$ \\
\hline & FB & 18.00 & 8.07 & $23.62 \pm 1.94$ & $1.68 \pm 0.18$ & $46.29 \pm 0.72$ & $29.28 \pm 3.79$ \\
\hline & $\mathrm{FV}$ & 15.00 & 6.73 & $26.98 \pm 0.41$ & $0.73 \pm 0.18$ & $44.47 \pm 1.55$ & $26.91 \pm 1.40$ \\
\hline & A & 15.50 & 6.95 & $22.93 \pm 0.73$ & $1.58 \pm 0.03$ & $41.23 \pm 4.56$ & $19.92 \pm 5.07$ \\
\hline & GF & 13.08 & 5.87 & $17.57 \pm 2.56$ & $1.35 \pm 0.13$ & $37.92 \pm 2.14$ & $25.57 \pm 2.44$ \\
\hline \multirow[t]{7}{*}{12} & $\mathrm{GN}$ & 4.00 & 1.79 & $10.32 \pm 1.41$ & $0.94 \pm 0.11$ & $25.21 \pm 2.58$ & $30.72 \pm 1.09$ \\
\hline & LF & 10.33 & 4.63 & $21.64 \pm 0.67$ & $0.99 \pm 0.31$ & $37.70 \pm 0.22$ & $26.40 \pm 3.20$ \\
\hline & $\mathrm{LN}$ & 6.25 & 2.80 & $16.69 \pm 1.18$ & $0.76 \pm 0.10$ & $29.40 \pm 1.68$ & $24.93 \pm 1.59$ \\
\hline & FB & 18.50 & 8.30 & $29.04 \pm 1.03$ & $2.97 \pm 0.21$ & $47.35 \pm 2.21$ & $29.12 \pm 2.80$ \\
\hline & $\mathrm{FV}$ & 18.00 & 8.07 & $29.11 \pm 0.65$ & $1.25 \pm 0.08$ & $47.68 \pm 1.00$ & $23.45 \pm 2.55$ \\
\hline & $\mathrm{A}$ & 15.00 & 6.73 & $25.76 \pm 1.59$ & $1.72 \pm 0.04$ & $42.34 \pm 2.06$ & $27.40 \pm 1.31$ \\
\hline & GF & 21.31 & 9.56 & $20.63 \pm 0.98$ & $1.62 \pm 0.23$ & $37.23 \pm 1.70$ & $24.59 \pm 0.56$ \\
\hline \multirow[t]{3}{*}{24} & GN & 3.75 & 1.68 & $10.25 \pm 2.20$ & $1.57 \pm 0.34$ & $24.37 \pm 2.87$ & $26.89 \pm 4.55$ \\
\hline & $\mathrm{LF}$ & 11.50 & 5.16 & $21.83 \pm 1.90$ & $1.40 \pm 0.20$ & $40.70 \pm 1.27$ & $26.62 \pm 1.74$ \\
\hline & $\mathrm{LN}$ & 4.00 & 1.79 & $17.53 \pm 0.68$ & $0.55 \pm 0.05$ & $34.91 \pm 2.29$ & $21.85 \pm 7.75$ \\
\hline
\end{tabular}

\section{References}

Abbad H., Jaafari S.E., Bort J. et al.: Comparative of the flag leaf and the ear photosynthesis with the biomass and grain yield of durum wheat under various water conditions and genotypes. Agronomie 24: 19-28, 2004.

Araus J.L., Brown H.R., Febrero A. et al.: Ear photosynthesis, carbon isotope discrimination and the contribution of respiratory $\mathrm{CO}_{2}$ to differences in grain mass in durum wheat. Plant Cell Environ. 16: 383-392, 1993.

Araus J.L., Slafer G.A., Reynolds M.P. et al.: Plant breeding and drought in C3 cereals: what should we breed for? - Ann. Bot.London 89: 925-940, 2002.

Arnon D.I.: Copper enzymes in isolated chloroplasts. Polyphenoloxidase in Beta vulgaris. - Plant Physiol. 24: 1-15, 1949.

Backhaus S., Kreyling J., Grant K. et al.: Recurrent mild drought events increase resistance toward extreme drought stress. Ecosystems 17: 1068-1081, 2014.

Boogaard R.V.D., Alewijnse D., Veneklaas E.J. et al.: Growth and water-use efficiency of 10 Triticum aestivum cultivars at different water availability in relation to allocation of biomass.
- Plant Cell Environ. 20: 200-210, 1997.

Bort J., Febrero A., Amaro T. et al.: Role of awns in ear wateruse efficiency and grain weight in barley. - Agronomie 14: 133-139, 1994.

Bort J., Brown R.H., Araus J.L.: Refixation of respiratory $\mathrm{CO}_{2}$ in the ears of C3 cereals. - J. Exp. Bot. 47: 1567-1575, 1996.

Carr D.J., Wardlaw I.F.: Supply of photosynthetic assimilates to grain from flag leaf and ear of wheat. - Aust. J. Biol. Sci. 18: $711,1965$.

Evans L.T., Wardlaw I.F., Fischer R.A.: Wheat. - In: Evans L.T. (ed.): Crop Physiology: Some Case Histories. Pp. 101-150, Cambridge Univ. Press, Cambridge 1975.

Farquhar G.D., Sharkey T.D.: Stomatal conductance and photosynthesis. - Annu. Rev. Plant Physio. 33: 317-345, 1982.

Flexas J., Medrano H.: Drought-inhibition of photosynthesis in C3 plants: stomatal and non-stomatal limitations revisited. Ann. Bot.-London 89: 183-189, 2002.

Friend A.D., Woodward F.I.: Evolutionary and ecophysiological responses of mountain plants to the growing season 
environment - Adv. Ecol. Res. 20: 59-124, 1990.

Gebbing T., Schnyder H.: ${ }^{13} \mathrm{C}$ labeling kinetics of sucrose in glumes indicates significant refixation of respiratory $\mathrm{CO}_{2}$ in the wheat ear. - Funct. Plant Biol. 28: 1047-1053, 2001.

Grundbacher F.J.: The physiological function of the cereal awn. - Bot. Rev. 29: 366-381, 1963.

Guerfel M., Beis A., Zotos T. et al.: Differences in abscisic acid concentration in roots and leaves of two young Olive (Olea europaea L.) cultivars in response to water deficit. - Acta Physiol. Plant. 31: 825-831, 2009.

Hu W., Huang C., Deng X. et al.: TaASR1, a transcription factor gene in wheat, confers drought stress tolerance in transgenic tobacco. - Plant Cell Environ. 36: 1449-1464, 2013.

Huseynova I.M.: Photosynthetic characteristics and enzymatic antioxidant capacity of leaves from wheat cultivars exposed to drought. - BBA-Biomembranes 1817: 1516-1523, 2012.

Imaizumi N., Usuda H., Nakamoto H. et al.: Changes in the rate of photosynthesis during grain filling and the enzymatic activities associated with the photosynthetic carbon metabolism in rice panicles. - Plant Cell Physiol. 31: 835-844, 1990.

Jia S., Lv J., Jiang S. et al.: Response of wheat ear photosynthesis and photosynthate carbon distribution to water deficit. Photosynthetica 53: 95-109, 2015.

Johnson R.C., Mornhinweg D.W., Ferris D.M. et al.: Leaf photosynthesis and conductance of selected Triticum species at different water potentials. - Plant Physiol. 83: 1014-1017, 1987.

Kraus T.E., McKersie B.D., Fletcher R.A.: Paclobutrazolinduced tolerance of wheat leaves to paraquat may involve increased antioxidant enzyme activity. - J. Plant Physiol. 145: 570-576, 1995.

Kriedemann P.: The photosynthetic activity of the wheat ear. Ann. Bot.-London 30: 349-363, 1966.

Lakshmi A., Ramanjulu S., Veeranjaneyulu K. et al.: Effect of $\mathrm{NaCl}$ on photosynthesis parameters in two cultivars of mulberry. - Photosynthetica 32: 285-289, 1996.

Lawlor D.W.: Limitation to photosynthesis in water-stressed leaves: stomata $v s$. metabolism and the role of ATP. - Ann. Bot.-London 89: 871-885, 2002.

Liu E.K., Mei X.R., Yan C.R. et al.: Effects of water stress on photosynthetic characteristics, dry matter translocation and WUE in two winter wheat genotypes. - Agr. Water Manage. 167: 75-85, 2016.

Martin B., Kebede H., Rilling C.: Photosynthetic differences among Lycopersicon species and Triticum aestivum cultivars. - Crop Sci. 34: 113-118, 1994.

Martinez D.E., Luquez V.M., Bartoli C.G. et al.: Persistence of photosynthetic components and photochemical efficiency in ears of water-stressed wheat (Triticum aestivum). - Physiol. Plantarum 119: 519-525, 2003.

Maydup M.L., Antonietta M., Guiamet J.J. et al.: The contribution of green parts of the ear to grain filling in old and modern cultivars of bread wheat (Triticum aestivum L.): evidence for genetic gains over the past century. - Field Crop. Res. 134: 208-215, 2012.

Morgan J.A., LeCain D.R.: Leaf gas exchange and related leaf traits among 15 winter wheat genotypes. - Crop Sci. 31: 443448, 1991.

Morgan J.M.: Osmotic adjustment in the spikelets and leaves of wheat. - J. Exp. Bot. 31: 655-665, 1980.

O'Brien T.P., Sammut M.E., Lee J.W. et al.: The vascular system of the wheat spikelet. - Funct. Plant Biol. 12: 487-511, 1985.

Parry M.A., Reynolds M., Salvucci M.E. et al. Raising yield potential of wheat. II. Increasing photosynthetic capacity and efficiency. - J. Exp. Bot. 62: 453-467, 2011.

Reynolds M.P., Mujeeb-Kazi A., Sawkins M.: Prospects for utilising plant-adaptive mechanisms to improve wheat and other crops in drought-and salinity-prone environments. - Ann. Appl. Biol. 146: 239-259, 2005.

Rodgers V.L., Hoeppner S.S., Daley M.J. et al.: Leaf-level gas exchange and foliar chemistry of common old-field species responding to warming and precipitation treatments. - Int. J. Plant Sci. 173: 957-970, 2012.

Royo C., Michelena A., Carrillo J.M. et al. Spanish durum wheat breeding program. - In: Nachit M.M., Baum M., Porceddu E. et al. (ed.): SEWANA (South Europe, West Asia and North Africa) Durum Research Network. - Proceedings of the SEWANA Durum Network Workshop, 20-23 March 1995. Pp. 80-87. ICARDA: Aleppo, Syria 1998

Saeidi M., Abdoli M.: Effect of drought stress during grain filling on yield and its components, gas exchange variables, and some physiological traits of wheat cultivars. - J. Agr. Sci. Tech.-Iran 17: 885-898, 2015.

Shimada T., Sugano S.S., Hara-Nishimura I.: Positive and negative peptide signals control stomatal density. - Cell Mol. Life Sci. 68: 2081-2088, 2011.

Shimshi D., Ephrat J.: Stomatal behavior of wheat cultivars in relation to their transpiration, photosynthesis, and yield. Agron. J. 67: 326-331, 1975.

Sikder S., Foulkes J., West H. et al.: Evaluation of photosynthetic potential of wheat genotypes under drought condition. Photosynthetica 53: 47-54, 2015.

Simmons S.R.: Growth, development and physiology. - In: Heyne E.G. (ed.): Wheat and Wheat Improvement. Pp. 77-113. American Society of Agronomy Inc., Madison 1987.

Singal H.B., Sheoran I.S., Singh R.: In vitro enzyme activities and products of ${ }^{14} \mathrm{CO}_{2}$ assimilation in flag leaf and ear parts of wheat (Triticum aestivum L.). - Photosynth. Res. 8: 113-122, 1986.

Skovmand B., Renolds M.P., Delacy, I.H.: Searching genetic resources for physiological traits with potential for increasing yield. - In: Renolds, M.P., Ortiz-Monasterio J.I., McNab A. (ed): Application of Physiology in Wheat Breeding. Pp. 17-28. CIMMYT, Mexico DF 2001

Tambussi E.A., Bort J., Guiamet J.J. et al.: The photosynthetic role of ears in $\mathrm{C}_{3}$ cereals: metabolism, water use efficiency and contribution to grain yield. - Crit. Rev. Plant Sci. 26: 1-16, 2007.

Tambussi E.A., Nogués S., Araus J.L.: Ear of durum wheat under water stress: water relations and photosynthetic metabolism. Planta 221: 446-458, 2005.

Teare I.D., Peterson C.J.: Surface area of chlorophyll-containing tissue on the inflorescence of Triticum aestivum L. - Crop Sci. 11: 627-628, 1971.

Teare I.D., Law A.G., Simmons G.F.: Stomatal frequency and distribution on the inflorescence of Triticum aestivum. - Can. J. Plant Sci. 52: 89-94, 1972.

Wallace J.S.: Increasing agricultural water use efficiency to meet future food production. - Agr. Ecosyst. Environ. 82: 105-119, 2000.

Wang X., Vignjevic M., Jiang D. et al.: Improved tolerance to drought stress after anthesis due to priming before anthesis in wheat (Triticum aestivum L.) var. Vinjett. - J. Exp. Bot. 65: 6441-6456, 2014.

Wardlaw I.F.: Interaction between drought and chronic high temperature during kernel filling in wheat in a controlled environment. - Ann. Bot.-London 90: 469-476, 2002. 
Wu Y.L., Guo Q.F., Luo Y., Tian. et al.: Differences in physiological characteristics between two wheat cultivars exposed to field water deficit conditions. - Russ. J. Plant Physl+ 61: 451-459, 2014.

Xu H.L., Ishii R.: Effects of water deficit on photosynthesis in wheat plants: IV. Response of photosynthesis to exogenous abscisic acid in different plant parts. - Plant Prod. Sci. 59: 384389, 1990.

Zhang Y., Wang Z., Wu Y. et al.: Stomatal characteristics of different green organs in wheat under different irrigation regimes. - Acta Agron. Sin. 32: 70-75, 2006.

Ziegler-Jöns A.: Gas-exchange of ears of cereals in response to carbon dioxide and light: II. Occurrence of a C3-C4 intermediate type of photosynthesis. - Planta 178: 164-175, 1989a. Ziegler-Jöns A.: Gas exchange of ears of cereals in response to $\mathrm{CO}_{2}$ and light: I. Relative contributions of parts of the ears of wheat, oat, and barley to the gas exchange of the whole organ. - Planta 178: 84-91, 1989 b. 